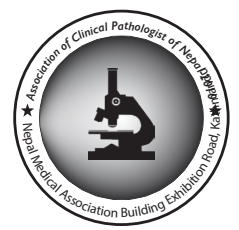

\title{
A study of gastrointestinal tract tumors at Kathmandu Medical College teaching hospital
}

\author{
Pradhan Sailesh Bahadur ${ }^{1}$, Pradhan Binita ${ }^{2}$, Maharjan Sailuja ${ }^{1}$,Thapa Prabin \\ Bikram $^{3}$ \\ ${ }^{I}$ Department of Pathology, Kathmandu Medical College teaching hospital, Kathmandu, Nepal. \\ ${ }^{2}$ Department of Emergency, Kathmandu Medical College teaching hospital, Kathmandu, Nepal. \\ ${ }^{3}$ Department of Surgery, Kathmandu Medical College teaching hospital, Kathmandu, Nepal.
}

\section{Keywords: \\ Benign; \\ Colorectal; \\ Malignant; \\ Polyp; \\ Tumour;}

\begin{abstract}
Background: Gastrointestinal tract tumour is responsible for more cancers and death than any other cancers. The tumour in GIT include the tumour of the Oral cavity, Esophagus, Stomach, Colon, Rectum, Liver, Gallbladder, Pancreas and Biliary tree.

Materials and methods: A cross sectional study was carried out among all the gastrointestinal tract tumours specimens received for histopathological examination in between January 2016 to June 2017 in Department of Pathology, Kathmandu Medical College Teaching Hospital. All tumors diagnosed either benign or malignant were included in this study. Ethical clearance was obtained from the Institutional Review Committee in KMCTH.

Results: Colorectum was found to be the most commonly involved site for malignant lesion comprising $40.2 \%$ among all malignant lesions followed by stomach comprising $28.6 \%$. Malignancy was found to be more prevalent among male with M:F ratio of 1.6:1 in colorectal region and 1.4:1 in stomach cancers. Regarding benign lesions (polyps), rectum was found to be the commonest site $(57.5 \%)$, followed by colon $(20.0 \%)$ and stomach, the least common site. Malignant lesions were more common among the age group of 51-60 years (37.66\%) with $70.13 \%$ above 50 years. Benign lesions were also found to be the most common above 50 years comprising 40.0 percent.
\end{abstract}

Conclusion: Rectum \& colon was found to be the most commonly involved site for both malignant and benign lesion. Malignancy were more prevalent among male and common above 50 years of age. However, malignant cases noted in the adult age group are a matter of great concern.

\section{Correspondence:}

Dr. Sailesh Bahadur Pradhan, MBBS, MD

Associate Professor, Department of Pathology

Kathmandu Medical College teaching hospital, Kathmandu, Nepal ORCID ID: 0000-0002-0784-1836

Email: saibinita@gmail.com

Received : November 15 2017 ; Accepted : January $28^{\text {th }} 2018$; Published : March $21^{\text {st }} 2018$

Citation: Pradhan SB, Pradhan B, Maharjan S,Thapa PB, A study of gastrointestinal tumors at Kathmandu Medical College Teaching Hospital. J Pathol Nep 2018; 1285-8. Doi: 10.3126/jpn. v8i1.19455

Copyright: This is an open-access article distributed under the terms of the Creative Commons Attribution 4.0 International License, which permits unrestricted use, distribution, and reproduction in any medium, provided the original author and source are credited.

\section{INTRODUCTION}

Cancer is a major health issue in the world despite significant development in the medical field. It is one of the major causes of morbidity and mortality worldwide. ${ }^{1}$ Gastrointestinal tract (GIT) tumour are responsible for more cancers and death than any other cancers. ${ }^{2}$ The tumour in GIT include the tumour of the oral cavity, esophagus, stomach, colon, rectum, liver, gallbladder, pancreas and biliary tree. Out of these, gastric cancers, colorectal cancers, liver cancers, and pancreatic cancers are the most common in Asia. ${ }^{3}$ Gastric and colorectal cancers are the major cancers of the GIT. As per incidence of the malignant disease, colorectum 
Table No 1: Distribution of Malignant lesion $(n=77)$

\begin{tabular}{|c|c|c|c|c|c|c|c|c|c|}
\hline \multirow[t]{2}{*}{ Tumor site } & \multicolumn{6}{|c|}{ Age group (years) } & \multirow[t]{2}{*}{ Total } & \multicolumn{2}{|c|}{ Gender } \\
\hline & $<30$ & $31-40$ & $41-50$ & $51-60$ & $61-70$ & $>71$ & & M & $\mathrm{F}$ \\
\hline Colorectal & 5 & 2 & 2 & 13 & 5 & 4 & $31(40.2 \%)$ & 19 & 12 \\
\hline Stomach & & 1 & 2 & 7 & 6 & 6 & $22(28.6 \%)$ & 13 & 9 \\
\hline Oesophagus & & & & & & 1 & $1 \quad(1.3 \%)$ & 1 & \\
\hline Appendix & & 1 & & & & & $1(1.3 \%)$ & 1 & \\
\hline Ampulla & & 1 & & 5 & & 1 & $7(9.1 \%)$ & 5 & 2 \\
\hline Cholangiocarcinoma & & & 2 & 3 & & & $5(6.5 \%)$ & 4 & 1 \\
\hline Gall bladder & & 1 & 2 & & 1 & & $4(5.2 \%)$ & 1 & 3 \\
\hline Pancrease & & & 3 & 1 & & & $4(5.2 \%)$ & & 4 \\
\hline CBD & & & 1 & & 1 & & $2(2.6 \%)$ & & 2 \\
\hline TOTAL & $5(6.5 \%)$ & $6(7.8 \%)$ & $12(15.6 \%)$ & $29(37.6 \%)$ & $13(16.9 \%)$ & $12(15.6 \%)$ & $77(100.0 \%)$ & 44 & 33 \\
\hline
\end{tabular}

comes third most common site among male \& second most common site among female worldwide. ${ }^{4,5}$ Likewise, the fifth most common site for cancer in the world is stomach. ${ }^{6}$ The progress of tumour development from benign to invasive cancer is a long process. ${ }^{7}$ Therefore, the invasive tumour can be prevented by early diagnosis of cancer and can reduce the morbidity and mortality related to an advanced stage. An attempt was made to find out the prevalence of benign \& malignant lesions in gastrointestinal \& hepatobiliary system in $\mathrm{KMCTH}$.

\section{MATERIALS AND METHODS}

A cross sectional study was carried out in the Department of Pathology, KMCTH during the period of eighteen months from January 2016 to June 2017. Ethical clearance was obtained from the institutional review committee in KMCTH. All the histopathologically proven tumour specimens of GI tract received in Department of Pathology were included in the study. The paraffin embedded sections stained with Haematoxylin and Eosin were taken for microscopic examination. The slides were examined by pathologists and data were recorded in the Microsoft Excel. Data analysis was performed using Microsoft Excel 2010.

\section{RESULTS}

A total of 117 cases of lesions were studied. Among these, 77 cases were malignant and 40 cases were benign. Colorectum was the most commonly involved site for malignant lesion comprising 40.2\% among all malignant lesion followed by stomach comprising $28.6 \%$. Malignancy was found to be more prevalent among male with $\mathrm{M}: \mathrm{F}$ ratio of $1.6: 1$ in colorectal region and $1.4: 1$ in stomach cancers except in gallbladder carcinoma where the $\mathrm{M}: \mathrm{F}$ ratio was $1: 3$. (Table 1) Regarding benign lesions (polyps), rectum was found to be the commonest site $(57.5 \%)$, followed by colon $(20.0 \%)$ and stomach is the least common site $(7.5 \%)$. (Table 2 )

Malignant lesions were found to be more common among the age group of 51-60 years (37.66\%) with 70.13\% above 50 years. Benign lesions were also found to be the most common above 50 years comprising $40.0 \%$ but $6.5 \%$ malignant cases out of all malignant cases were observed

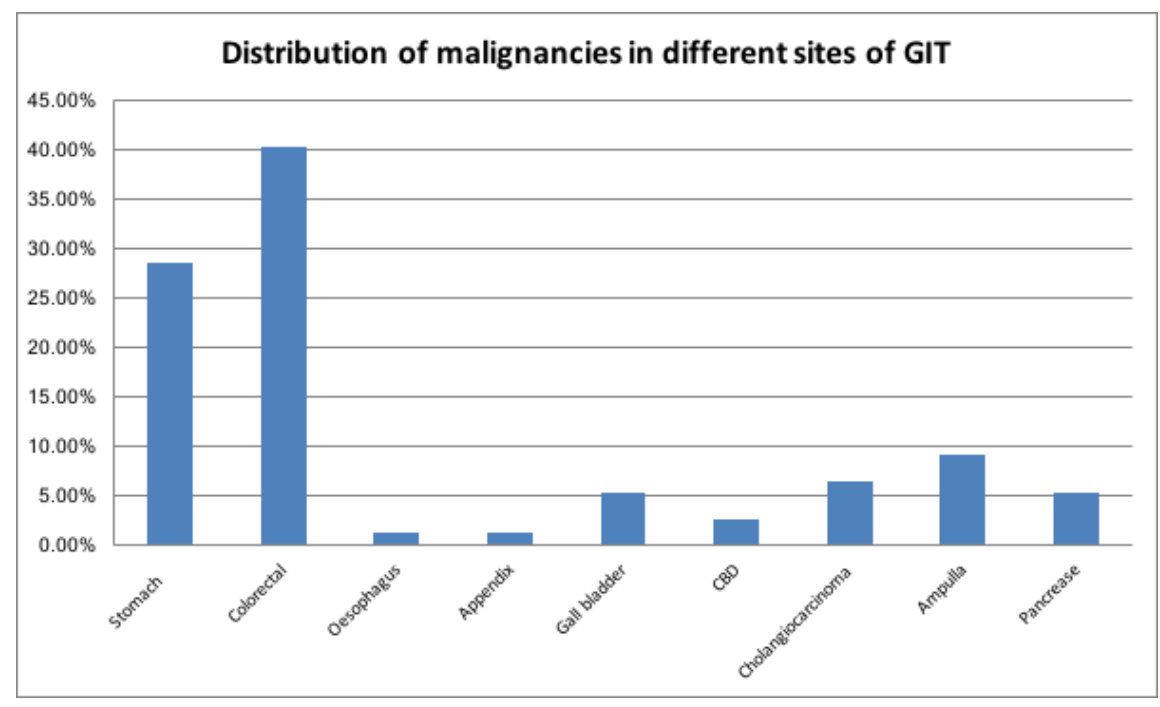

Figure 1: Distribution of malignancies in different sites of GI System 
Table 2: Benign Polypoidal lesions at various sites of gastrointestinal tract

\begin{tabular}{|c|c|c|c|c|c|c|c|c|c|}
\hline \multirow[t]{2}{*}{ Polyp site } & \multirow[t]{2}{*}{ Types } & \multicolumn{5}{|c|}{ Total (years) } & \multirow{2}{*}{$\begin{array}{c}\text { Total } \\
\text { Total }\end{array}$} & \multicolumn{2}{|c|}{ Gender } \\
\hline & & $11-20$ & $21-30$ & $31-40$ & $41-50$ & $>\mathbf{5 0}$ & & M & $\mathbf{F}$ \\
\hline \multirow{7}{*}{ Rectal polyp } & Retention & & 1 & 1 & & & 2 & & 2 \\
\hline & Inflammatory & 1 & 1 & 2 & 1 & 2 & 7 & 3 & 4 \\
\hline & Hyperplastic & & & 1 & & 1 & 2 & 2 & \\
\hline & Tubular adenoma & & 1 & & & 4 & 5 & 1 & 4 \\
\hline & Adenomatous & & & & & 6 & 6 & 3 & 3 \\
\hline & Fibroepithelial & & & & & 1 & 1 & 1 & \\
\hline & Total & 1 & 3 & 4 & 1 & 14 & $23(57.5 \%)$ & 10 & 13 \\
\hline \multirow{5}{*}{ Colonic polyp } & Adenomatous & & 1 & & & 1 & 2 & 1 & 1 \\
\hline & Hyperplastic & & & 1 & & & 1 & 1 & \\
\hline & Inflammatory & & 1 & 2 & & & 3 & 2 & 1 \\
\hline & Tubular adenoma & & & & 1 & 1 & 2 & 2 & \\
\hline & Total & & 2 & 3 & 1 & 2 & $8(20.0 \%)$ & 6 & 2 \\
\hline \multirow{4}{*}{ Sigmoid polyp } & Tubulovillous & & & 1 & & & 1 & 1 & \\
\hline & Inflammatory & & 1 & 1 & & & 2 & & 2 \\
\hline & Tubular adenoma & & & & 1 & 2 & 3 & 2 & 1 \\
\hline & Total & & 1 & 2 & 1 & 2 & $6(15.0 \%)$ & 3 & 3 \\
\hline \multirow{3}{*}{ Gastric polyp } & Hyperplastic & & & & & 1 & 1 & & 1 \\
\hline & Inflammatory & 1 & 1 & & & & 2 & & 2 \\
\hline & Total & 1 & 1 & & & 1 & $3(7.5 \%)$ & & 3 \\
\hline Grand total & & $2(5.0 \%)$ & $7(17.5 \%)$ & $9(22.5 \%)$ & $3(7.5 \%)$ & $19(47.5 \%)$ & $40(100.0 \%)$ & 19 & 21 \\
\hline
\end{tabular}

among adult age group (<30 years). (Table 1 and 2$)$

Among the studied population, most common malignancies in gastrointestinal tract was colorectum, followed by stomach, whereas, esophageal and appenidceal malignancies were the least common site (fig. 1).

Among the benign lesions $(n=40)$, colon was the most common site comprising $37(92.5 \%)$ cases. In colon rectal polyp was the most frequent $(\mathrm{n}=23 ; 57.5 \%)$ and histologically inflammatory pseudopolyp was the most common $(\mathrm{n}=7 ; 17.5 \%)$. Among neoplastic polyp of colon tubular adenoma was the most common $(\mathrm{n}=9 ; 22.5 \%)$ followed by adenomatous polyp $(n=8 ; 20 \%)$. Table 2 Most of the benign colorectal polyps were seen in the patients older than 50 years of age. All the tubular adenoma and adenomatous polyps were observed in patients after 40 years of age, except one from each type, which was seen in young age group (21-30 years age)

\section{DISCUSSION}

Cancer is one of the major causes of morbidity and mortality in the world. ${ }^{1}$ Among all the tumours, gastrointestinal tract tumours are responsible for more cancers and death than any other cancers. ${ }^{2}$ The most common cancers in the GIT system in Asia includes Gastric cancers, Colorectal cancers, Liver cancers, Esophageal cancers and Pancreatic cancers. As per incidence colorectal cancer (CRC) is the third and Gastric cancer is the fifth most common cancer in Asia. ${ }^{4-6}$ Similarly, hepatocellular carcinoma comes sixth whereas esophageal cancer is the eighth most common cancer worldwide. ${ }^{8}$

The reason of high prevalence could be due to old age, population growth and exposure to the risk factors like smoking, chemical, obesity, Helicobacter pylori, HBV, $\mathrm{HCV}$, limitation of early cancer detection and treatment services. ${ }^{9-13}$

Here in our study, out of 117 cases of lesions of GI system, 77 cases were malignant and 40 cases were benign. Colorectum was found to be the most commonly involved site for malignant lesion comprising $40.2 \%$ among all malignant lesion. Colorectal carcinoma was found to be more common among the age group of 51-60 years which was similar to the findings of a study done by Shah $\mathrm{S}$ et al. ${ }^{14}$ It is a matter of great concern that out of all colorectal cancers, $22.6 \%$ cases were found below 40 years which was $28.77 \%$ in a study of Shah et al. ${ }^{14}$ Malignancy was found to be more prevalent among male with $\mathrm{M}$ : $\mathrm{F}$ ratio of 1.6:1. The finding of Kansakar et $a 1^{15}$ was found to be $4: 3$ however, it was found to be equal in as study done by Shah $\mathrm{S}$ et a ${ }^{14}$ and Khan MR et al. ${ }^{16}$

Stomach was found to be the second most commonly involved site comprising $28.6 \%$ however it was only $19.2 \%$ and $15.9 \%$ in a study done by Mohammad AM et $\mathrm{al}^{17}$ and Jose L et al ${ }^{18}$ respectively. Gastric carcinoma was 
found to be slightly more prevalent among male with $\mathrm{M}$ : F ratio of 1.4:1 but it was found to be $3: 1$ in a study done by Mohammad AM et al. ${ }^{17}$ Regarding age involvement, the finding of Mohammad AM et $\mathrm{a}^{17}$ is similar to our finding as Gastric carcinoma was found to be less prevalent below 50 years $(13.6 \%)$.

Most of the malignancy arises from the pre-existing polyps, so determination of potential risk of malignancy of the polyp is essential for the treatment. Rectum was found to be the commonest site $(57.5 \%)$, followed by Colon (20.0\%), Sigmoid colon $15.0 \%$ and Stomach the least common site (7.5\%). However in a study done by Mirzaie AZ et a $1^{19}$ \& ElBadry AI et al ${ }^{7}$, Colon was found to be the most commonly involved site.

Benign lesions were also found to be more common above 50 years of age comprising $47.5 \%$, followed by $31-40$ years age group $(22.5 \%)$ which is similar with findings of other studies. ${ }^{7,19,20,21}$ In our study, both genders were found to be almost equally involved with mild female predominance $(\mathrm{M}: \mathrm{F}=1: 1.1)$. However prevalence was more common among male in a study of Mirzaie AZ et al. ${ }^{19}$

\section{CONSLUSION}

Rectum \& Sigmoid colon were found to be the most commonly involved site for both malignant and benign lesion followed by Stomach. Malignancy is more prevalent among male and common above 50 years of age however malignant cases noted in adult age group is a matter of great concern.

\section{Conflict of interest: None}

\section{REFERENCES}

1. Ferlay J, Soerjomataram I, Dikshit R, et al. Cancer incidence and mortality worldwide: Sources, methods and major patterns in GLOBOCAN 2012. Int J Cancer 2014. Crossref

2. Sung J, Ng E, Lin JT, et al. On behalf of the Asia Pacific GI Oncology Summit Group. Digestive Cancer Management in Asia: Position Statements- a report on GI Oncology Summit in 2011. J Gastroenterol Hepatol 2012; 27:1417-22. Crossref

3. Ferlay J, Shin HR, Bray F, Forman D, Mathers C, Parkin DM. Estimates of worldwide burden of cancer in 2008: GLOBOCAN 2008. Int J Cancer. 2010 Dec 15;127:2893-917. Crossref

4. Sung JJY, Lau JYW, Goh KL, Leung WK. for the on Asia Pacific Working Group on Colorectal Cancer. Increasing incidence of colorectal cancer in Asia: implications for screening. Lancet Oncol 2005;6:871-6. Crossref

5. Mohandas KM. Colorectal cancer in India: controversies, enigmas and primary prevention. Indian J Gastroenterol. 2011;30:3-6. $\underline{\text { Crossref }}$
6. GLOBOCAN Cancer Fact Sheets: stomach Cancers. Crossref

7. El-Badry AI, Abdalla MN, Aref WM, Kamel MH, Ishak EA, Farah BSH. Prevalence of Colonic Polyps among Egyptians, Retrospective Study . Journal of American Science 2012;8:394-6.

8. Fact Sheets by cancer. Crossref

9. Youn HS, Ko GH, Chung MH, Lee WK, Cho MJ,Rhee KH. Pathogenesis and prevention of stomach cancer. J Korean Med Sci 1996;11:373-85. Crossref

10. Huxley R; Asia Pacific Cohort Studies Collaboration. The role of lifestyle risk factors on mortality from colorectal cancer in populations of the Asia-Pacific region. Asian Pac J Cancer Prev 2007;8:191-8. $\underline{\text { Crossref }}$

11. Pourhoseingholi MA, Fazeli Z, Zali MR, Alavian SM. Burden of hepatocellular carcinoma in Iran; Bayesian projection and trend analysis. Asian Pac J Cancer Prev 2010;11:859-62. Crossref

12. Yang L, Parkin DM, Li L, Chen Y. Time trends in cancer mortality in China: 1987-1999. Int J Cancer 2003;106:771-83. Crossref

13. Larsson SC, Permert J, Hakansson N, Naslund I, Bergkvist L, Wolk A. Overall obesity, abdominal adiposity, diabetes and cigarette smoking in relation to the risk of pancreatic cancer in two Swedish population-based cohorts. Br J Cancer 2005;93:1310-5. Crossref

14. Shah S, Shrestha S, Shah JN, Paudyal S. Clinico-pathological characteristics of colorectal carcinoma at university teaching hospital, Nepal. Journal of Patan Academy of Health Sciences. 2014;1:35-8.

15. Kansakar P, Singh Y .Changing Trends of Colorectal Carcinoma in Nepalese Young Adults. Asian Pac J Cancer Prev 2012;13:3209-12. $\underline{\text { Crossref }}$

16. Khan MR, Bari H, Zafar SN, Raza SA. Impact of age on outcome after colorectal cancer surgery in the elderly - a developing country perspective. BMC Surg. 2011;11:17. Crossref

17. Mohammad AM, Magar S LR, Anil SA. Histopathological study of gastric cancer at teritiary care hospital. IOSR JDMS 2016;15:29-32.

18. Jose L, Nalappat S, Sisidharan VP. A clinico-pathological study of carcinoma stomach. Ind J Pathol Microbiol 995;38:73-9.

19. Mirzaie AZ, Abolhasani M, Moghaddam RM, Kadivar M. The Frequency of Gastrointestinal Polyps in Iranian Population. Iran J Pathol 2012;7:183-9.

20. Nam JH, Yang $\mathrm{CH}$. Clinical characteristics and risk factors of colon polyps in gyeongju and pohang area. Korean J Gastroenterol 2008;52:142-9. Crossref

21. Bond JH. Polyp guideline: diagnosis, treatment, and surveillance for patients with colorectal polyps. Practice parameters committee of the American college of gastroenterology. Am J Gastroenterol 2000;95:3053-63. Crossref 